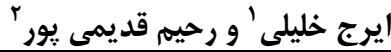

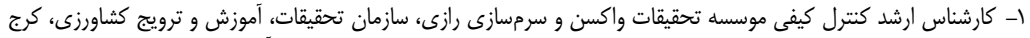

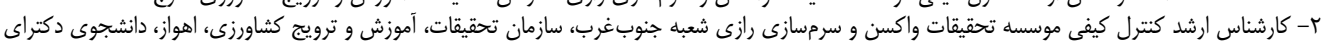

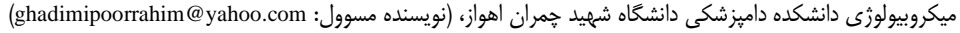
تاريخ دريافت:

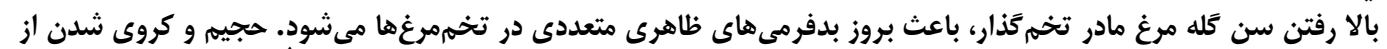

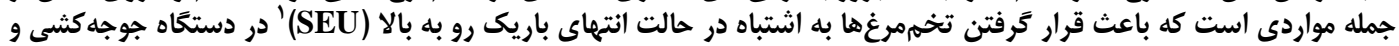

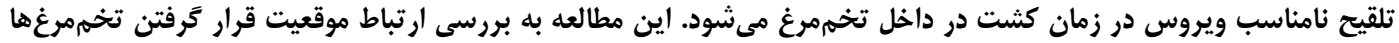

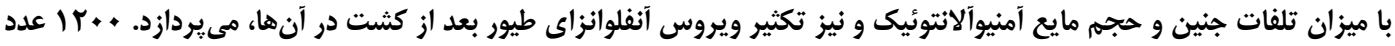

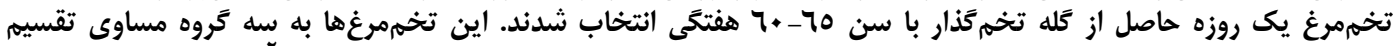

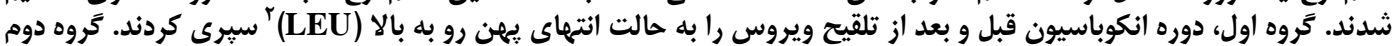

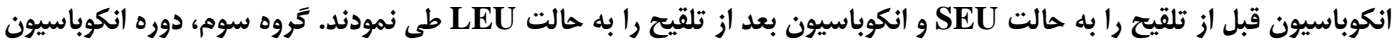

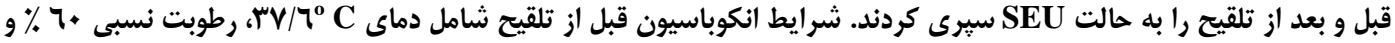

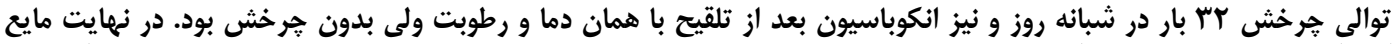

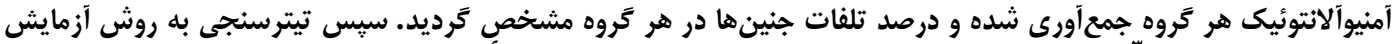

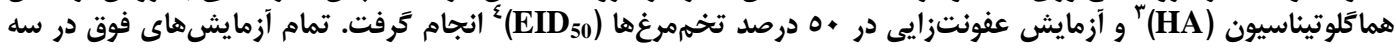

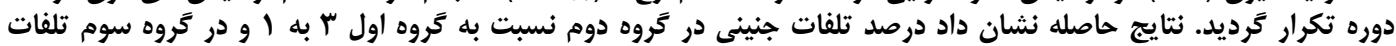

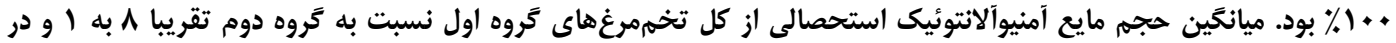

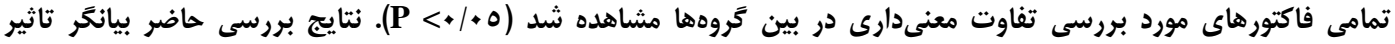

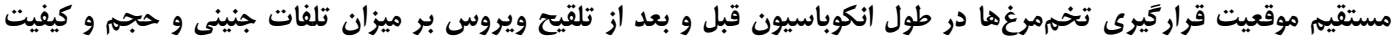

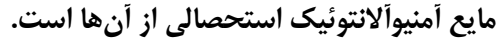

وازههاى كليدى: تخممرغ جنيندار، انكوباسيون، موقعيت تخممرغ، مايع آمنيوآلانتوئيك

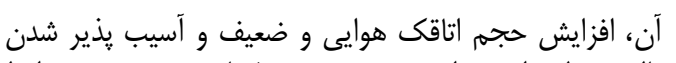

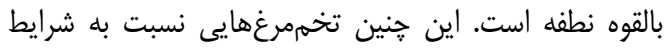

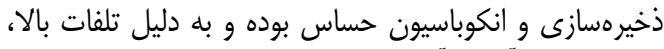

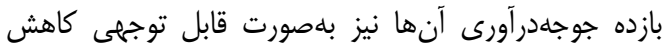

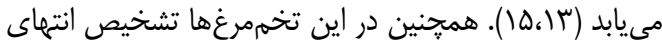

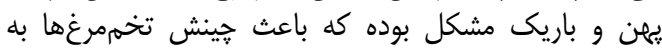

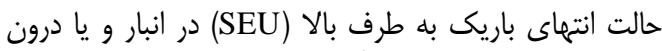

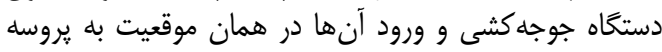

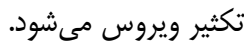

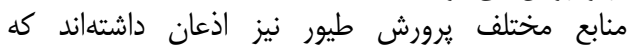

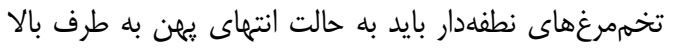
(LEU)

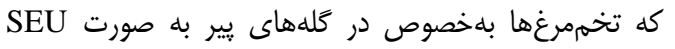

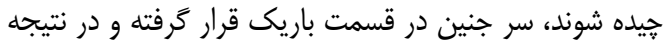

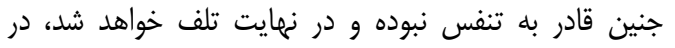

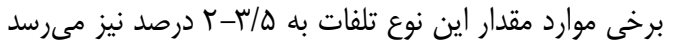

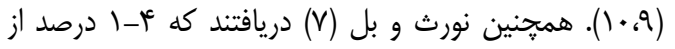

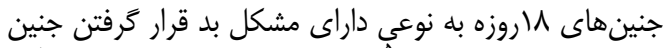

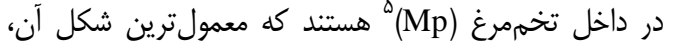

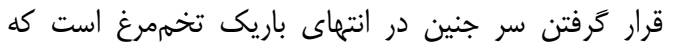
مىتواند به علت بالا بودن سن كله مادر، باريك برعكس قرار كر فتنن
مقدمه

يكى از روشهاى مرسوم براى تكثير ويروسها استفاده از

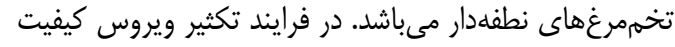

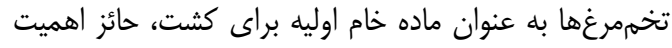

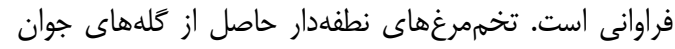

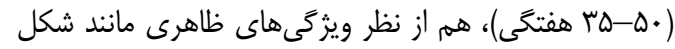

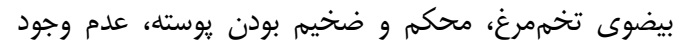

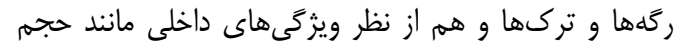

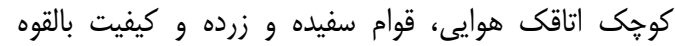

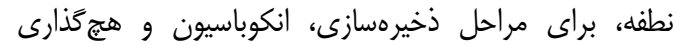

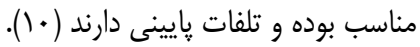

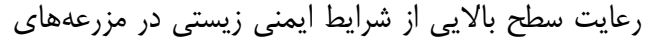

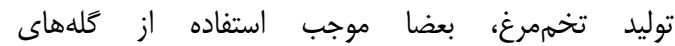

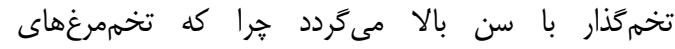

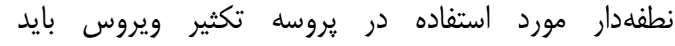

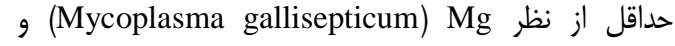
(Mycoplasma synoviae) Ms

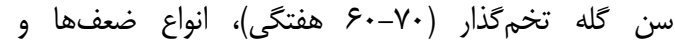

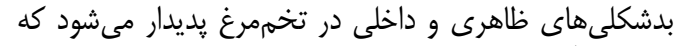

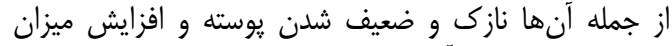
ركهها و تركها در آن، افزايش وزن تخممرغ و و كروى شدن 
كروه اول: بلهورت LEU خِيده شدند و بعد از تلقيح نيز به همان صورت باقى ماندند.

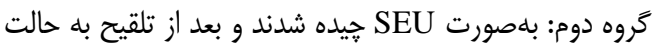
LEU

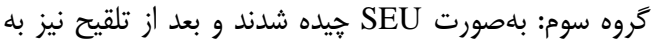
همان صورت باقى ماندند. انكوباسيون قبل از تلقيح

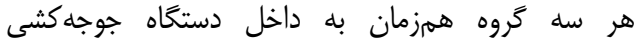

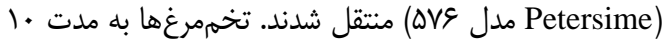
روز در دماى C C C C

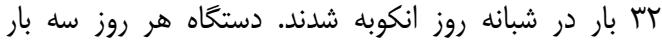

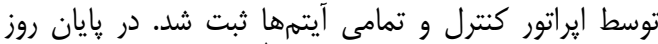

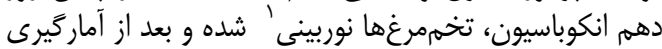

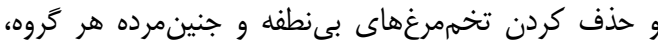

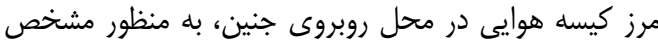

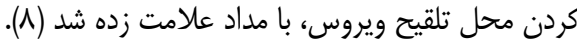
آمادهسازى بذر مجل تلفيح ويروس،

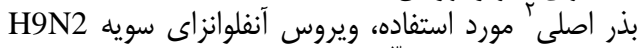

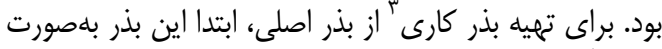

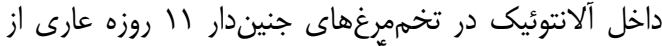

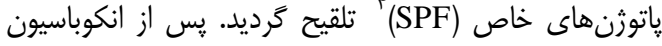

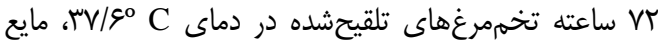

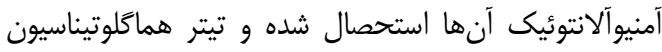

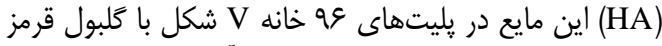

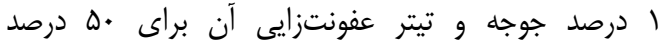
تخممرغها ( EID

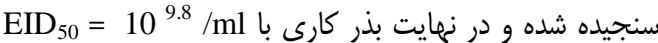
تو تلقيح بذر ويروس در تخممرغها و انكوباسيون بعد از تلقيح

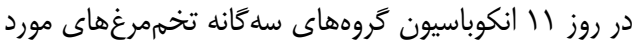

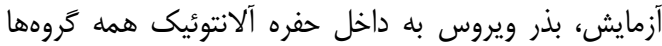

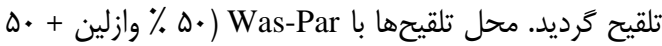

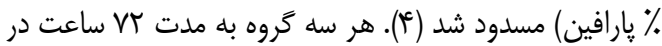

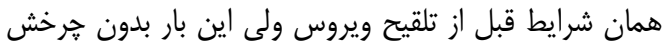

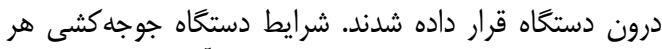

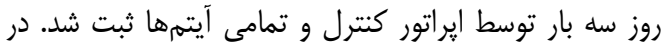

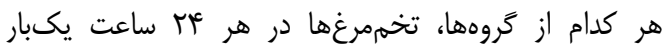

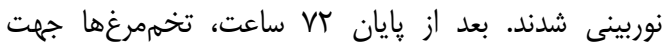

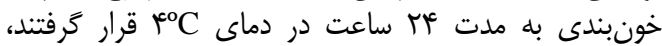

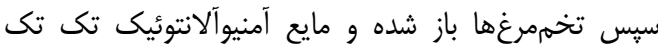

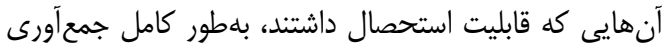

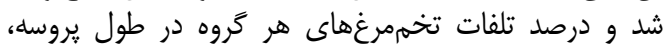

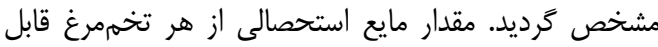

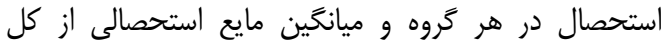

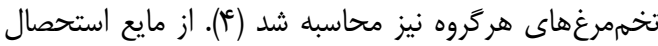

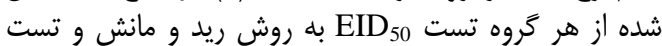

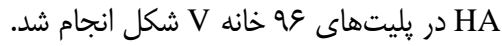

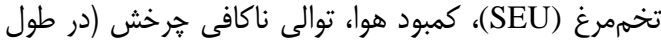

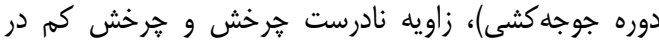

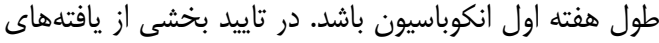

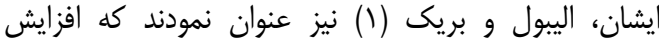

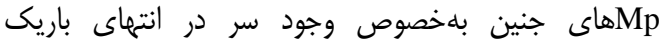

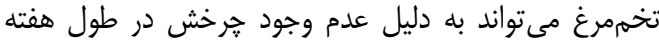

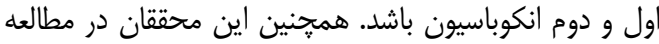

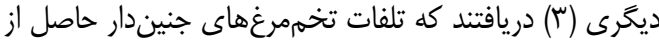

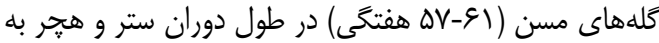

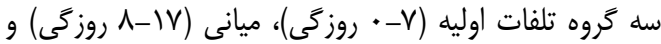

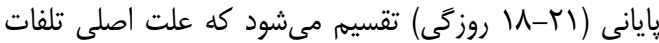

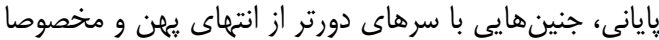

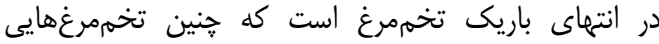

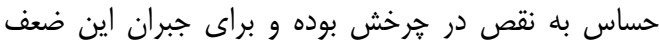

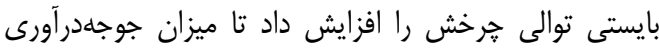

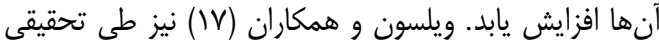

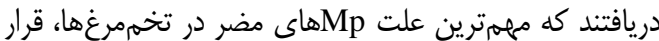

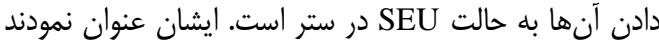

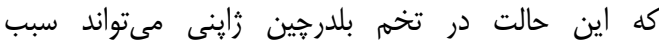

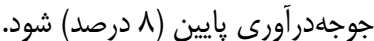

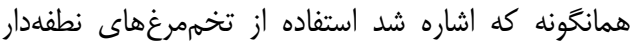

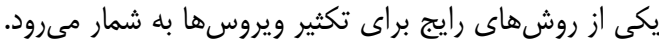

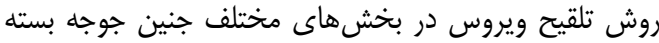

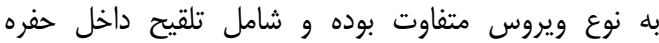

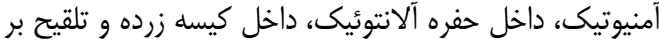

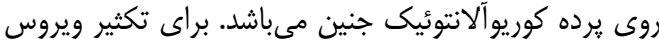

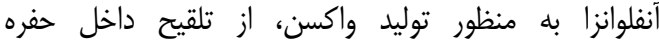

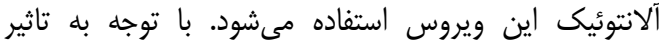

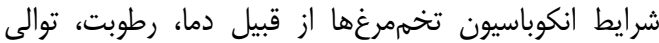

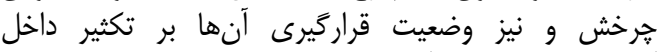

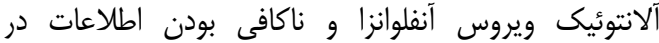

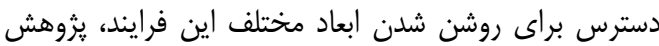

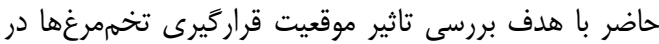

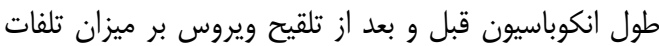

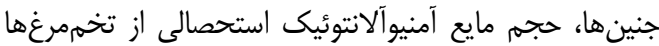

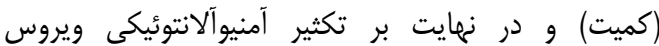
آنفلوانزاى طيور در آنها (كيفيت)، طراحى كرديد.

\section{مواد و روشها نها نها

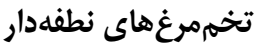

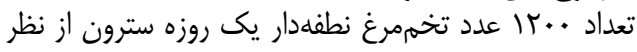

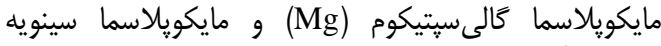

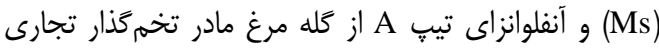

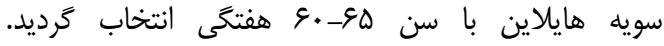

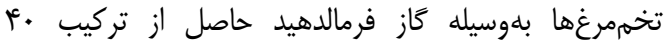

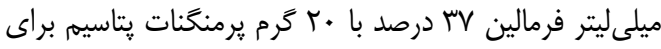

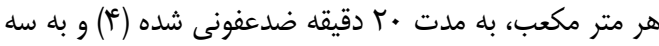

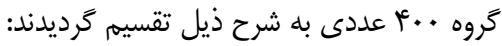

3-Work Seed 4- Specific Pathogen Free 
دوم اين ميزان به Vع درصد رسيد. بنابراين درصد كل

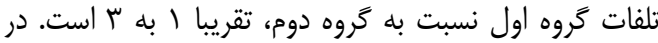

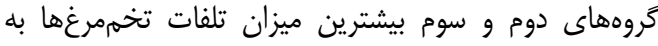

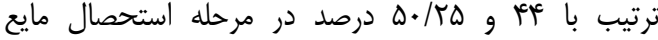

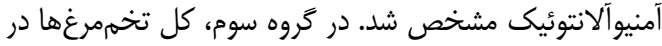

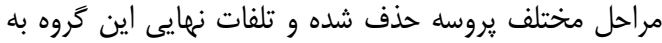

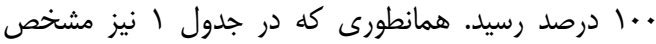

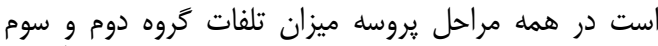

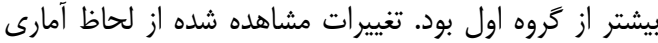

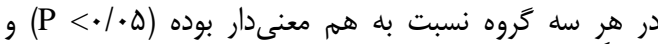
كاملاً منطبق با كنايج اخذ شده توسط ساير محققان است

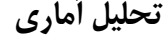
در بررسى حاضر، كليه آزمايشها در سها دوره تكرار كراديد.

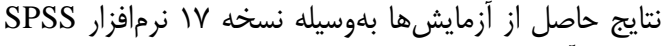

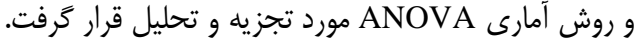

\section{نتايج و بحثث}

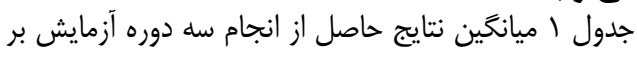

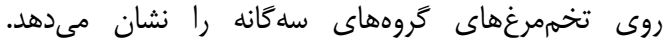

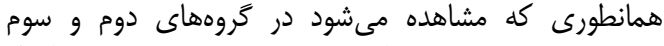

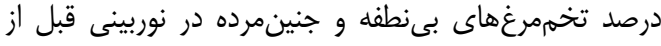

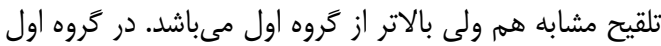

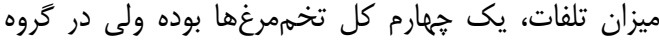

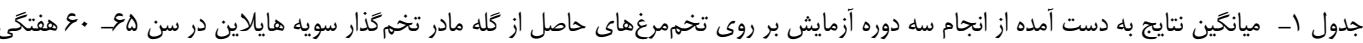
Table 1.The average of the results of three replicates on eggs from $\mathrm{Hy}$-line laying breeder flock at 60-65 weeks of age

\begin{tabular}{|c|c|c|c|c|c|c|c|c|c|c|c|c|}
\hline \multirow{3}{*}{$\begin{array}{c}\operatorname{EID}_{50} \\
(1 . x / m l)\end{array}$} & \multirow{3}{*}{$\begin{array}{l}\mathrm{HA} \\
\left(2^{\mathrm{X}}\right)\end{array}$} & \multicolumn{2}{|c|}{ آمنيوآلانتوئينيك استحصايعلى } & \multirow{3}{*}{ 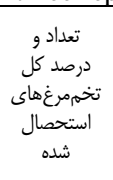 } & \multicolumn{6}{|c|}{ تعداد و درصد تلفات } & \multirow{3}{*}{ ترغل } & \multirow{3}{*}{ كروه } \\
\hline & & \multirow{2}{*}{ تخمم مرغها } & \multirow{2}{*}{ ازمت هر قابل } & & \multirow[b]{2}{*}{ كل } & \multirow{2}{*}{ 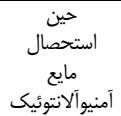 } & \multirow{2}{*}{ |زازبيتى بعد } & \multirow{2}{*}{ ساز تلقت بعد } & \multicolumn{2}{|c|}{ نوربينى قبل از تلقيح } & & \\
\hline & & & & & & & & & بى بطفه & جنينمرده & & \\
\hline \multirow[t]{2}{*}{$X=9 / 7^{a}$} & $1.0^{2}$ & $V / \& \pm \cdot /\left.\right|^{a}$ & $1 \cdot / / \pm \cdot / R \Delta^{a}$ & $r \cdot \mid \pm 1 r^{a}$ & $99 \pm 1 r^{2}$ & $r T \pm E / r^{a}$ & $\Delta \pm \Gamma / q^{a}$ & $r \pm \Gamma / q^{a}$ & $\Lambda \pm r^{a}$ & $\Delta r \pm q^{a}$ & f.. & 0 \\
\hline & $X=$ & & & $V \Delta / r \Delta \pm \Psi$ & $r \Psi / V \Delta \pm \Psi$ & $\Delta / \Delta \pm 1 / \Delta$ & $1 / T \Delta \pm \cdot / 9$ & $\cdot / \Delta \pm \cdot / 8$ & $r / \Delta \pm \cdot / V$ & $\mid r \pm r / r$ & & اول \\
\hline$X=N / 9^{D}$ & $X=\Lambda^{0}$ & $\cdot / 9 \pm \cdot / 1^{0}$ & $\varphi \pm \cdot / \wedge q^{0}$ & $\begin{array}{l}Q \xi \pm \backslash N / r^{D} \\
Y \Psi \pm \psi / \Delta\end{array}$ & $\begin{array}{c}r \cdot \psi \pm / N / r^{0} \\
\gamma \xi \pm \psi / \Delta\end{array}$ & $\begin{array}{c}|V q \pm| \digamma / Q^{D} \\
\kappa \Psi \pm r / q\end{array}$ & $\begin{array}{l}r \lambda \pm q / l^{D} \\
r \pm r / r\end{array}$ & $\begin{array}{l}19 \pm \% / \Delta^{\circ} \\
F / V \Delta \pm 1 / 1\end{array}$ & $\begin{array}{l}r \Psi \pm r^{\mathrm{ab}} \\
\Delta / \Delta \pm 1\end{array}$ & $\begin{array}{l}\Delta q \pm \mid)^{\text {ala }} \\
\mid f / v \Delta \pm r / \Delta\end{array}$ & f.. & دوروه \\
\hline \multirow[t]{2}{*}{-} & - & - & 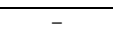 & $\cdot \pm^{c}$ & $f \cdot \cdot \pm \cdot^{c}$ & $r \cdot I \pm T V / V^{C}$ & $V \backslash \pm I r / I^{c}$ & $\varphi q \pm v^{c}$ & $r \cdot \pm \Delta / /^{D}$ & $9^{4} \pm N \Lambda^{0}$ & $f .$. & كرو \\
\hline & & & &. \pm & $1 . . \pm$. & $\Delta \cdot / \pi \Delta \pm \varepsilon / q$ & $I V / V \Delta \pm r$ & $11 \pm 1 / 2$ & $\Delta \pm 1 / r$ & $19 \pm r / r$ & & سوم \\
\hline
\end{tabular}

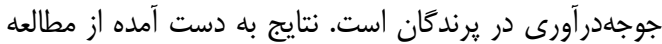

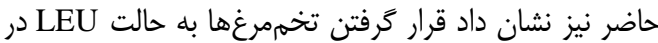

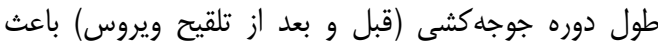

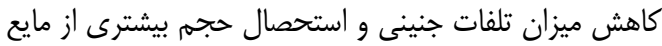
آمنيوآلانتوئيك مى شيز تلفود. بر اساس مطالعات مورائس و همكاران (ع) (ع) انكوباسيون تخم

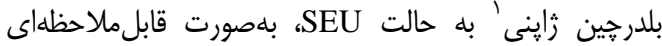

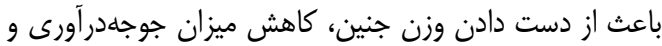

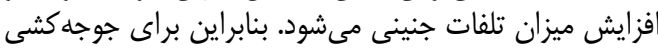

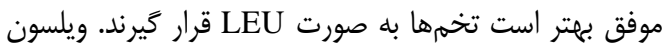

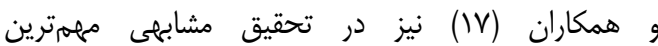

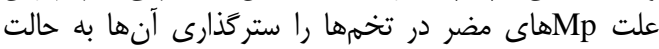

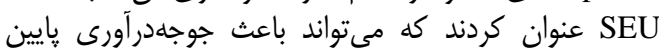

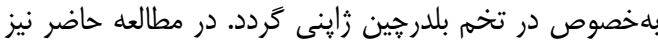

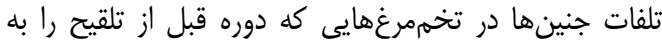

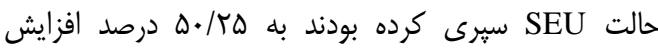
يافت. - الت

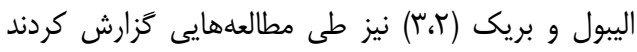

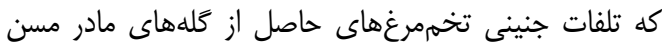

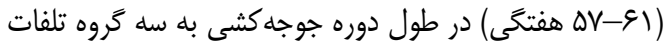

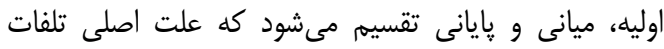
يايانى، جنينهايى با سرهاى دورتر از انتهاى يهن مئن و مخصوصا
همجنين در جدول ا ميانگين حجم مايع آمنيوآلانتوئيك

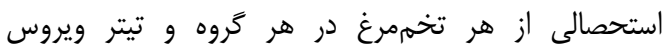

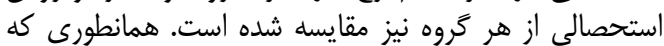

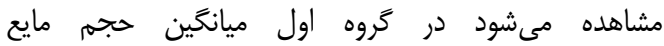

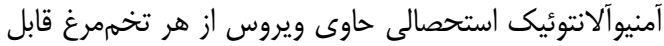

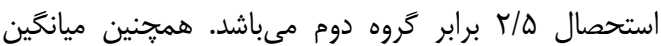

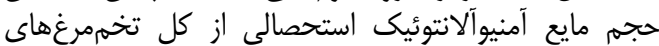

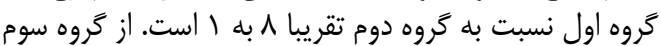

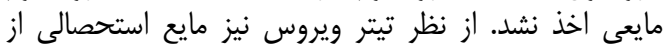

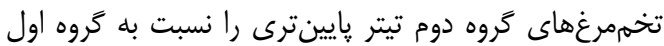

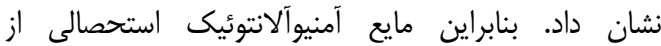

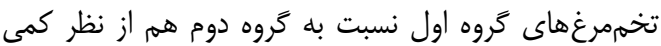

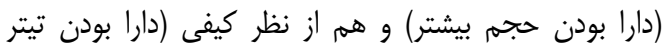

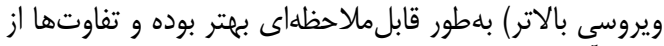

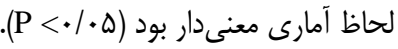

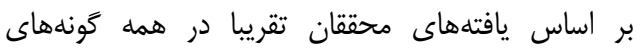

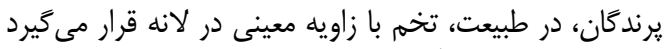

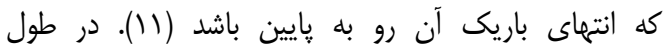

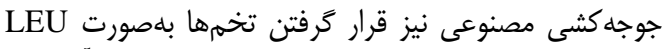

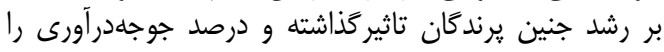

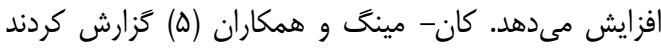

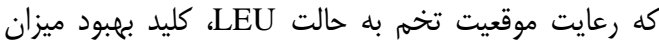




\begin{tabular}{|c|c|}
\hline 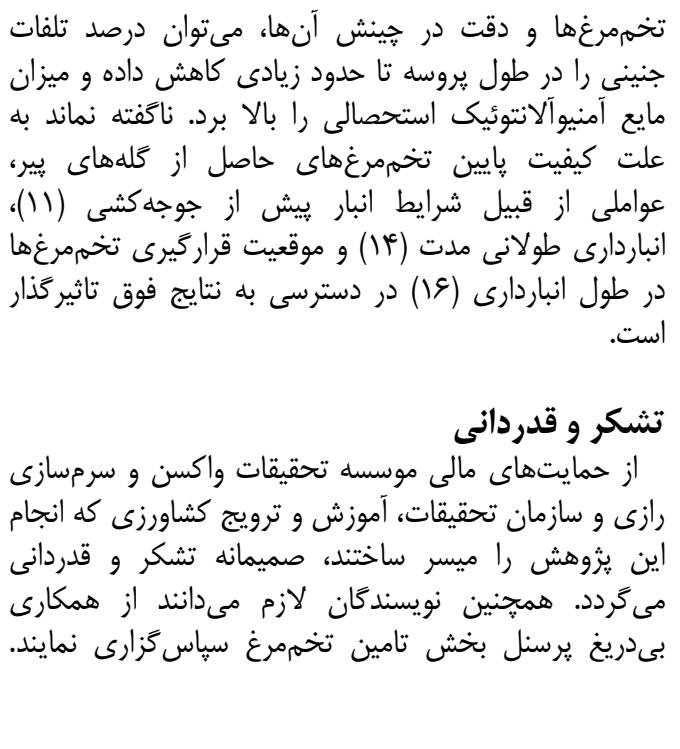 & 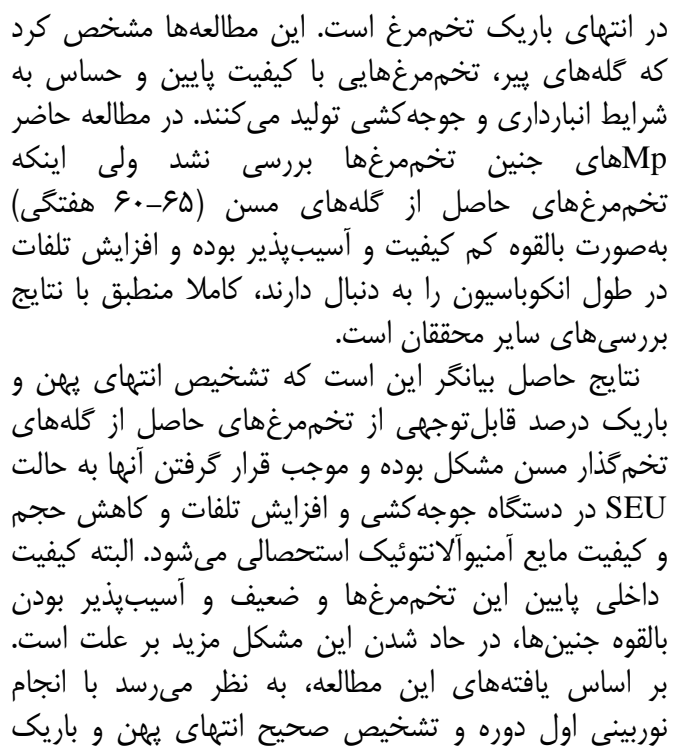 \\
\hline
\end{tabular}

1. Elibol, O. and J. Brake. 2004. Identification of critical periods for turning broiler hatching eggs during incubation. British Poultry Science, 45(5): 631-637.

2. Elibol, O. and J. Brake, 2006. Effect of egg turning angle and frequency during incubation on hatchability and incidence of unhatched broiler embryos with head in the small end of the egg. Poultry Science, 85(8): 1433-1437.

3. Elibol, O. and J. Brake, 2008. Effect of egg position during three and fourteen days of storage and turning frequency during subsequent incubation on hatchability of broiler hatching eggs. Poultry Science, 87(6): 1237-1241.

4. FAO. Animal production and health paper 89 (by Dr. V. Palya Phylaxia Vet. Biol. Com. Budapest, Hungary). pp: 10-56.

5. Kun-Ming, M., M. Ayako, I. Atsuhi and Y. Norio. 2007. The asymmetry of avian egg-shape: an adaption for reproduction on dry land. Journal of Anatomy, 210(6): 741-748.

6. Moraes, T.G.V., J.M. Romao, R.S.C. Teixeira and W.M. Cardoso. 2008. Effects of egg position in artifificial incubation of Japanese quail eggs (Coturnix Japonica). Animal Reproduction, 5(1-2): 5054.

7. North, M.O. and D.D. Bell, 1990. Commercial chicken production manual, $4^{\text {th }}$ ed. (New York, NY, Van Nostrand Reinhold Press), pp: 42-49.

8. OIE (The World Organisation for Animal Health). 2011. Manual of diagnostic tests and vaccines for terrestrial animals. Chapter 2.3.4. pp: 465-481. In: Avian Influenza, $6^{\text {th }}$ ed. Office International des Epizooties, Paris, France.

9. Pashmi, M. and S. Moradi. 2010. Buildings, facilities and equipment for poultry farming. Agricultural, Research, Education and Extension Organization Press: 219-230 (In Persian).

10. Poorreza, J. and G. Sadeghi, 2008. Poultry management. Arkane Danesh Press: 101-121 (In Persian).

11. Proudfoot, F.G. 1967. Advance note on the hatchability of chicken eggs stored small end up. Canadian Journal of Animal Science, 47: 142-143.

12. Reed, L.J. and H. Muench. 1938. A simple method of estimating fifty percent endpoints. American Journal of Hygiene, 27(3): 493-497.

13. Saki, A.A., M. Haghi and E. Rahmatnejad. 2014. The effect of various levels of dietary protein and methionine on the laying hen's performance and egg characteristics in late laying cycle. Research on Animal Production, 5(10): 13-25.

14. Sally, E.G. 2002. A basic laboratory manual for the small-scale production and testing of I-2 newcastle disease vaccine: 44-49.

15. Soroush, Z., S. Salari, M. Sari, J. Fayazi and S. Tabatabaii. 2015. Effects of different levels of zinc on performance, egg quality traits and some blood parameters of laying hens. Research on Animal Production, 6(11): 19-27.

16. Tiwari, A.K.R. and T. Maeda. 2005. Effects of egg storage position and injection of solutions in stored eggs on hatchability in chikens (Gallus domesticus): research note. The Journal of Poultry Science, 42(4): 356-362.

17. Wilson, H.R., S.L. Neuman, A.R. Eldred and F.B. Mather. 2003. Embryonic malpositions in broiler chickens and bobwhite quail. The Journal of Applied Poultry Research, 12: 14-23. 


\title{
The Effect of Eggs Condition in Incubation Period on Embryos Deaths and Amnio-allantoic Fluid Volume in Laying Breeders to Use Them in Virus Replication
}

\section{Iraj khalili ${ }^{1}$ and Rahim Ghadimipour ${ }^{2}$}

\author{
1- Masters Degree of Quality Control, Razi Vaccine and Serum Research Institute, Agricultural Research Education \\ and Extension Organization (AREEO), Karaj \\ 2- Masters Degree of Quality Control, Razi Vaccine and Serum Research Institute, Agricultural Research Education \\ and Extension Organization (AREEO), Ahwaz; Ph.D. Student of Microbiology, Faculty of Veterinary Medicine, \\ Shahid Chamran University, Ahwaz (Ghadimipoorrahim@yahoo.com) \\ Received: June 22, $2015 \quad$ Accepted: March 5, 2016
}

\begin{abstract}
The numerous apparent malformations of eggs from laying breeder flocks are affected by the increased age of the flocks. The bulking and spinning of eggs causes them to be placed in small end up (SEU) condition in the incubation period and eventually inoculation of the virus is done incorrectly. Present study was designed to investigate the effect of egg condition on embryos deaths, amnioallantoic fluid volume, and the influenza virus replication rate. 1200 one-day-old embryonated chicken eggs from breeder flock at 60-65 weeks of age were divided in three groups. The first group underwent the incubation period before and after inoculation of the virus in large end up (LEU) condition. The second group spent the incubation period pre and post inoculation of the virus in SEU and LEU positions, respectively. The third group passed the incubation period before and after the inoculation in SEU condition. Prior to inoculation of the virus, all groups were incubated for 11 days at $37.6^{\circ} \mathrm{C}$ and $60 \%$ relative humidity $(\mathrm{RH})$, and turned 32 times daily. After inoculation, the eggs were incubated for three days at the same conditions but without turning. Ultimately, in each group, the amnio-allantoic fluid was collected and the percentage of embryos deaths was determined. Titration assays were performed using hem agglutination (HA) and egg infective dose $50\left(\mathrm{EID}_{50}\right)$ tests. All experiments were performed in three replicates. The results showed that the percentage of embryos deaths was 3:1 in the second group in comparison to the first group. In the third group, casualties were $100 \%$. Mean of extracted amnio-allantoic fluid volume from total eggs of first group in comparison to the second group was approximately $8: 1$. There were significant differences between the groups in all factors $(\mathrm{p}<0.05)$. Based on the current study findings, the condition of eggs during the incubation period before and after inoculation of the virus has a direct effect on embryos deaths, and the volume and quality of the amnio-allantoic fluid.
\end{abstract}

Keywords: Amnio-allantoic fluid, Egg condition, Embryonated chicken eggs, Incubation 